\title{
Band-gap variation and a self-redox effect induced by compositional deviation in ZnxGa2O3+x:Cr3+ persistent phosphors
}

\section{$\operatorname{AUTHOR}(\mathrm{S})$ :}

Zhuang, Yixi; Ueda, Jumpei; Tanabe, Setsuhisa; Dorenbos, Pieter

\section{CITATION:}

Zhuang, Yixi ... [et al]. Band-gap variation and a self-redox effect induced by compositional deviation in ZnxGa2O3+x:Cr3+ persistent phosphors. Journal of Materials Chemistry C 2014, 2(28): 5502-5509

\section{ISSUE DATE:}

2014-04-29

URL:

http://hdl.handle.net/2433/198760

\section{RIGHT:}

This journal is (C) The Royal Society of Chemistry 2014.; This is not the published version. Please cite only the published version.; この論文は 出版社版でありません。引用の際には出版社版をご確認ご利用くださ い。 


\title{
ARTICLE
}

Cite this: DOI: 10.1039/x0xx00000x

Received 00th January 2012, Accepted 00th January 2012

DOI: $10.1039 / \times 0 \times x 00000 x$

www.rsc.org/

\section{Band-gap variation and self-redox effect induced by compositional deviation in $\mathrm{Zn}_{\mathrm{x}} \mathrm{Ga}_{2} \mathrm{O}_{3+\mathrm{x}}: \mathrm{Cr}^{3+}$ persistent phosphors}

\author{
Yixi Zhuang, ${ }^{* a}$ Jumpei Ueda, $^{b}$ Setsuhisa Tanabe ${ }^{c}$ and Pieter Dorenbos ${ }^{d}$
}

\begin{abstract}
We made a systematic investigation on the optical properties of non-doped and Cr-doped $\mathrm{Zn}_{\mathrm{x}} \mathrm{Ga}_{2} \mathrm{O}_{3+\mathrm{x}}(0.98 \leq \mathrm{x} \leq 1.02)$ spinel crystals. Absorption, photoluminescence excitation, and persistent luminescence excitation spectra indicated that the bottom of conduction band (CB) was affected (i) by compositional deviation from stoichiometry or (ii) by atmosphere control in a similar way. By constructing an energy level diagram, a broad distribution of trap depth in a $\mathrm{Cr}^{3+}$-doped $\mathrm{Zn}_{\mathrm{x}} \mathrm{Ga}_{2} \mathrm{O}_{3+\mathrm{x}}$ sample with composition of $\mathrm{Zn}$ excess or in one prepared in $\mathrm{O}_{2}$ atmosphere was attributed to lowering of the CB bottom, which resulted in faster decay of persistent luminescence in these two samples. Defect chemical reactions revealed that the anti-sites species of $\mathrm{Zn}_{\mathrm{Ga}}{ }_{\mathrm{G}}$ may be the reason for lowering of the $\mathrm{CB}$ bottom. A self-redox effect of $\mathrm{Cr}$ ions induced by the compositional deviation was found and explained by the defect reactions. The investigation indicated that the composition with slight $\mathrm{Zn}$ deficiency is important to obtain a narrow distribution of trap depths and longer persistent luminescence, however the self-reduction effect of $\mathrm{Cr}$ ions in the composition of Zn deficiency also need to be considered.
\end{abstract}

\section{Introduction}

Persistent phosphors, which continue light emission after removal of the excitation source, have long been of scientific interests due to their important applications as luminous paints, identification markers, or optical memories. ${ }^{1-5}$ Recently, another attractive application in in vivo medical imaging system by using nano-sized persistent particles as optical probe was proposed by a French group, which focused more attention on the persistent phosphors. ${ }^{6,7}$ One of the key requirements for in vivo imaging application is that the luminescence wavelength of persistent particles should be inside the biological window from 650 to $1300 \mathrm{~nm}$ where the optical signal shows rather high transmittance through the biological tissues. ${ }^{8}$ This spectral requirement rules out most $\mathrm{Eu}^{2+}$-activated phosphors showing excellent persistent performance in the blue or green regions. ${ }^{9-}$ ${ }^{13}$ Until now, only few $\mathrm{Eu}^{2+}$-activated compounds were known to exhibit persistent luminescence beyond $650 \mathrm{~nm}$. Most of them are hygroscopic sulfides and unsuitable for biological application. ${ }^{14,15}$ Alternatively, several $\mathrm{Cr}^{3+}$-activated gallate phosphors, especially $\mathrm{ZnGa}_{2} \mathrm{O}_{4}$-based spinel crystals, were reported showing long-lasting persistent luminescence from 680 to $1000 \mathrm{~nm}$, which were considered as promising optical materials for in vivo imaging application. ${ }^{16-26}$
Bessière et al. firstly reported red persistent luminescence at around $695 \mathrm{~nm}$ in $\mathrm{Cr}^{3+}$-doped $\mathrm{ZnGa}_{2} \mathrm{O}_{4}$ crystals in 2011. ${ }^{16} \mathrm{Pan}$ and Allix et al. greatly improved the red persistent luminescence by partially substituting Ge to form $\mathrm{Zn}_{1+\mathrm{x}} \mathrm{Ga}_{2-}$ ${ }_{2 \mathrm{x}} \mathrm{Ge}_{\mathrm{x}} \mathrm{O}_{4}$ solid solution. The persistent luminescence was detectable by night vision equipment up to $360 \mathrm{~h}$ after the excitation source was removed. ${ }^{17,18}$ We also found that by codoping $\mathrm{Bi}_{2} \mathrm{O}_{3}$ into $\mathrm{Zn}_{0.98} \mathrm{Ga}_{2} \mathrm{O}_{3.98}$ crystals, the intensity of red persistent luminescence can be improved by 10 times. The absolute intensity (radiance) of persistent luminescence in $\mathrm{Zn}_{0.98} \mathrm{Ga}_{2} \mathrm{O}_{3.98}: \mathrm{Cr}, \mathrm{Bi}$ phosphors was comparable to that in $\mathrm{SrAl}_{2} \mathrm{O}_{4}$ :Eu,Dy phosphors. ${ }^{19}$ Recently, Abdukayum et al. succeeded to demonstrate in vivo imaging experiments by using $\mathrm{Zn}_{1+\mathrm{x}} \mathrm{Ga}_{2-2 \mathrm{x}} \mathrm{Ge}_{\mathrm{x}} \mathrm{O}_{4}$ : $\mathrm{Cr}, \mathrm{Pr}$ nano-particles. The feasibility, including $\mathrm{Cr}^{3+}$ persistent luminescence duration, particle biocompatibility, water solubility etc. was proved in this study. ${ }^{20}$ Although notable progress on intensity improvement or nanoparticulation has been made, the $\mathrm{Cr}^{3+}$-doped $\mathrm{ZnGa}_{2} \mathrm{O}_{4}$ crystals need further investigation in order to understand the energy levels governing the red persistent luminescence. As mentioned by Bessière et al. in their milestone paper, a sample with $\mathrm{Zn}$ deficiency in the composition showed more intense persistent luminescence than other samples. ${ }^{16}$ The composition of $\mathrm{Zn}$ deficiency was adopted by many researchers. However, the reason for the composition dependency has not been given. 
A systematic study on persistent luminescence induced by compositional deviation may give much information on structure variation, and offer theoretical guidance for the design of better persistent phosphors.

In this paper, we introduce methods to discuss the persistent luminescence mechanism by building an energy level diagram (Sec. 2.1) and to discuss structural variation by using a defect formation equation (Sec. 2.2), which are applied in the following sections. In Sec. 3, synthesis conditions (nominal composition and applied atmosphere) of prepared samples and important details about optical measurements are described. The results are summarized and discussed in Sec. 4. It starts from a discussion on band-gap variation in non-doped $\mathrm{Zn}_{\mathrm{x}} \mathrm{Ga}_{2} \mathrm{O}_{3+\mathrm{x}}$ samples prepared in different conditions (either composition or atmosphere) (Sec. 4.1), and moves to optical characterizations in various $\mathrm{Cr}^{3+}$-doped $\mathrm{Zn}_{\mathrm{x}} \mathrm{Ga}_{2} \mathrm{O}_{3+\mathrm{x}}$ samples by discussing the change of valence state in $\mathrm{Cr}$ ions (Sec. 4.2) and the variation of energy level diagram as well as $\mathrm{Cr}^{3+}$ persistent luminescence performance (Sec. 4.3). Some conclusions are made in Sec. 5.

\section{Methodology}

\subsection{Building an energy level diagram to discuss the persistent luminescence mechanism}

It is indispensable to understand the mechanism of persistent luminescence for successful material synthesis. However, it was a bigger challenge to give a clear explanation for the observed persistent phenomenon, rather than to discovered an excellent material (sometimes accidently) in the past., ${ }^{9,27}$ Several models, generally by using a simple energy level diagram to describe the charge carrier transfer process between active centers and trap centers, were proposed by different researchers. ${ }^{4}$ Two major controversial points in these models are (i) the species of charge carrier from the luminescent center (whether a negative electron or a positive hole) captured by the trap center and (ii) the path of the trapping process (whether through the conduction band or through the valence band or by a quantum tunnelling effect in the band-gap). The persistent luminescence mechanism can be correctly determined only when the relative energy locations of (i) the valence band (VB) and the conduction band (CB) of the host, (ii) the ground state (GS) and excited states (ES) of the luminescent center as well as, (iii) the trap energy levels are clear. It is significant to determine the relative locations of these energy bands/levels in the research of persistent phosphors, by using various optical characterizations.

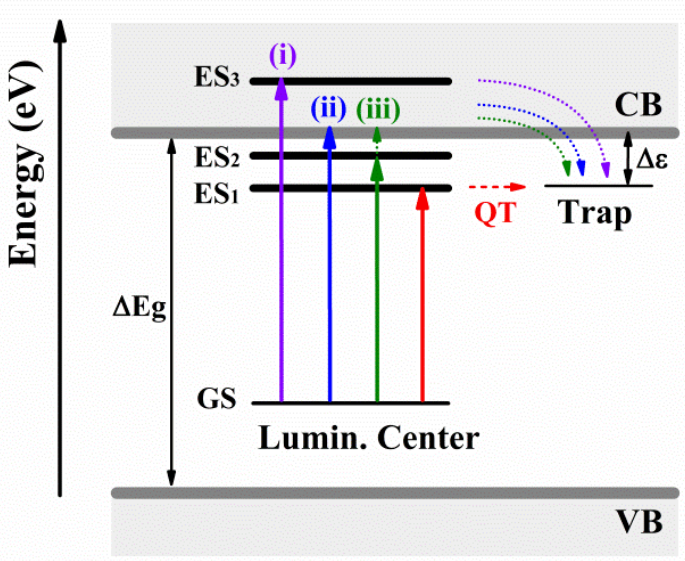

Fig. 1 Schematic energy level diagram showing typical electron trapping processes. CB and VB are referred to conduction band and valence band of the host; GS and ES are ground state and excited states of the luminescent center. Arrows (i), (ii), and (iii) show three different excitation ways for electron moving to trap center through CB. Quantum tunneling (QT) effect is another possible path for electron trapping.

In recent publications, most experimental results confirm that an electron from a luminescent center captured by a trap center through the $\mathrm{CB}$ is the most efficient path for charge carrier trapping process, although the contribution of quantum tunnelling cannot be completely excluded. Possible trapping processes are shown in Fig. 1. The electron can be excited to the CB in three ways: (i) from GS to ES above the bottom of $\mathrm{CB}$; (ii) directly from GS to $\mathrm{CB}$; (iii) from GS to ES below the bottom of CB. In the third case, the electron can "jump" to CB with thermal energy, which was named thermally assisted photoionization process. The specific trapping process is determined by the relative locations of the energy bands/levels.

Dorenbos has developed an empirical model to determine the GS and ES (f and d orbitals) of $\mathrm{R}^{2+}$ and $\mathrm{R}^{3+}$ (rare earth ions in +2 and +3 valence states) relative to $\mathrm{CB}$ and $\mathrm{VB}$, which was a very useful tool to discuss the persistent properties in many rare-earth-activated phosphors. ${ }^{28-31}$ We consider that the same research approach can be applied to transition-metal-activated materials. Firstly, a host referred binding energy (HRBE) scheme is adopted, where the energy of the VB top is defined as zero. The HRBE of the CB bottom can be determined by the band-gap energy from absorption spectra of a non-doped sample. In the second step, we need to know the relative locations of energy levels of luminescent center (GS and ES) relative to the energy bands of the host (CB and $V B$ ). Photoconductivity excitation (PCE) spectra, persistent luminescence excitation spectra (PersLE), or photoluminescence excitation (PLE) spectra measurements are useful to evaluate the energy of electronic transition from the GS to the bottom of CB (arrow ii in Fig. 1). Also, the energy values for 3d-3d intra-transitions from GS to various ES can be read from absorption spectra or PLE spectra in a transitionmetal-doped sample. Finally, the depth of trap levels $(\Delta \varepsilon$, thermal activation energy) can be determined in the measurement of thermoluminescence (TL) glow curves. 


\subsection{Using Kröger-Vink notation to discuss structural variation}

In many persistent phosphors, synthesis condition (compositional deviation from stoichiometry or atmosphere control) show either positive effect or negative effect on the persistent luminescence performance. ${ }^{32-35}$ It is helpful if we know what kind of structural change occurs, i.e., which species of defects are created in a real synthesis process. Since direct detection of the defects is generally difficult or unavailable, a theoretical method by writing defect chemical reactions in Kröger-Vink notation can be used. ${ }^{36}$ The key defects responsible for the optical properties could be inferred by connecting the applied synthesis condition with the obtained optical properties, although experimental proof is usually required to verify this. For example, the great improvement of persistent luminescence in $\mathrm{SrAl}_{2} \mathrm{O}_{4}: \mathrm{Eu}^{2+}$ phosphor by $\mathrm{Dy}^{3+}$ codoping was as attributed to the formation of Dy $\mathrm{S}_{\mathrm{Sr}} \cdot$ defect as following: ${ }^{37}$

$$
\mathrm{Dy}_{2} \mathrm{O}_{3}+2 \mathrm{Al}_{2} \mathrm{O}_{3} \stackrel{\mathrm{SrAl}_{2} \mathrm{O}_{4}}{\longrightarrow} 2 \mathrm{Dy}_{\mathrm{Sr}}^{\bullet}+4 \mathrm{Al}_{\mathrm{Al}}^{\mathrm{x}}+8 \mathrm{O}_{\mathrm{O}}^{\mathrm{x}}+2 \mathrm{e}^{\prime}+\frac{1}{2} \mathrm{O}_{2} \uparrow
$$

In Sec. 4, we will show what kinds of anti-sites may be created under certain conditions and how these defects affect the optical properties in $\mathrm{Zn}_{\mathrm{x}} \mathrm{Ga}_{2} \mathrm{O}_{3+\mathrm{x}}: \mathrm{Cr}^{3+}$ phosphors by using the Kröger-Vink notation to describe defect chemical reactions.

\section{Experimental Procedures}

\subsection{Sample preparation}

Poly-crystalline ceramics were prepared by using a solid-state reaction method. The chemical reagents, $\mathrm{ZnO}(4 \mathrm{~N}), \mathrm{Ga}_{2} \mathrm{O}_{3}(4 \mathrm{~N})$, and $\mathrm{Cr}_{2} \mathrm{O}_{3}(3 \mathrm{~N})$, were used as starting materials. The starting materials were ground in an alumina mortar to form homogeneous and fine powder mixtures. Pellets ( $0.8 \mathrm{~g}$ and $\phi 15$ $\mathrm{mm}$ ) were shaped from the powder mixtures with a uniaxial loading of $50 \mathrm{MPa}$ in a stainless steel mold. The compacts were carefully moved to an electric furnace and fired at $1300{ }^{\circ} \mathrm{C}$ for $5 \mathrm{~h}$.

Nominal composition (the molar ratio of $\mathrm{Zn}$ to $\mathrm{Ga}$ ) and applied atmosphere $\left(\mathrm{O}_{2}\right.$ partial pressure) were used as two variables to investigate their effects on optical properties. Various synthesis conditions for non-doped $\mathrm{Zn}_{\mathrm{x}} \mathrm{Ga}_{2} \mathrm{O}_{3+\mathrm{x}}$ samples are shown in Table 1. Firstly the atmosphere was fixed as Air and the composition was varied from $2 \% \mathrm{Zn}$ deficiency (Zn-d), stoichiometric (Zn-s), to $2 \% \mathrm{Zn}$ excess (Zn-e) to obtain samples non-d-Air, non-s-Air, and non-e-Air, respectively. Then the composition was kept as stoichiometric and the gas flow was changed from pure $\mathrm{N}_{2}\left(\mathrm{P}_{\mathrm{O} 2}=0 \%\right)$, Air $\left(\mathrm{P}_{\mathrm{O} 2}=21 \%\right)$, to pure $\mathrm{O}_{2}\left(\mathrm{P}_{\mathrm{O} 2}=100 \%\right)$ to obtain samples non-s- $\mathrm{N}_{2}$, non-s-Air, and non-s- $\mathrm{O}_{2}$. In Table 2, Cr-doped $\mathrm{Zn}_{\mathrm{x}} \mathrm{Ga}_{2} \mathrm{O}_{3+\mathrm{x}}$ samples were prepared in the same synthesis conditions except for $0.5 \mathrm{~mol} \%$ substitution of $\mathrm{Cr}_{2} \mathrm{O}_{3}$ for $\mathrm{Ga}_{2} \mathrm{O}_{3}$.
Table 1 Nominal compositions and applied atmospheres of non-doped $\mathrm{Zn}_{\mathrm{x}} \mathrm{Ga}_{2} \mathrm{O}_{3+\mathrm{x}}$ poly-crystalline ceramics. The samples were notated as (dopant)(composition)-(atmosphere). d, s, and e were referred to $2 \% \mathrm{Zn}$ deficiency, stoichiometric, and $2 \% \mathrm{Zn}$ excess in the composition. $\mathrm{N}_{2}$, Air, and $\mathrm{O}_{2}$ corresponded to gas flow of pure $\mathrm{N}_{2}$, Air, and pure $\mathrm{O}_{2}$.

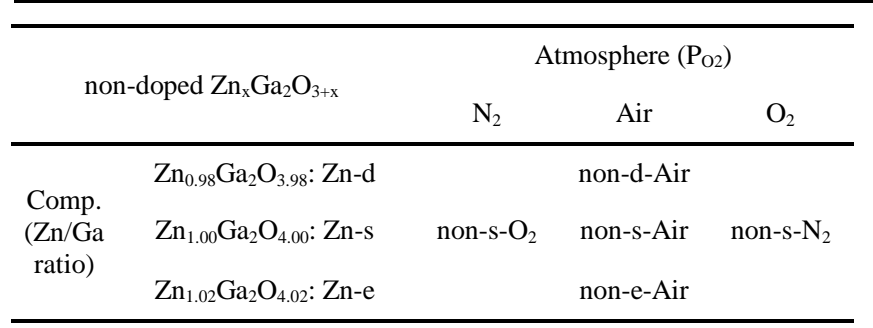

Table 2 Nominal compositions and applied atmospheres of Cr-doped $\mathrm{Zn}_{\mathrm{x}} \mathrm{Ga}_{2} \mathrm{O}_{3+\mathrm{x}}$ poly-crystalline ceramics. All the synthesis conditions were the same with the non-doped samples except for using $0.5 \mathrm{~mol} \% \mathrm{Cr}_{2} \mathrm{O}_{3}$ as dopant.

\begin{tabular}{|c|c|c|c|c|}
\hline & \multirow{2}{*}{ Cr-doped $\mathrm{Zn}_{\mathrm{x}} \mathrm{Ga}_{2} \mathrm{O}_{3+\mathrm{x}}$} & \multicolumn{3}{|c|}{ Atmosphere $\left(\mathrm{P}_{\mathrm{O} 2}\right)$} \\
\hline & & $\mathrm{N}_{2}$ & Air & $\mathrm{O}_{2}$ \\
\hline \multirow{3}{*}{$\begin{array}{c}\text { Comp. } \\
\text { (Zn/Ga } \\
\text { ratio) }\end{array}$} & $\mathrm{Zn}_{0.98}\left(\mathrm{Ga}_{0.995} \mathrm{Cr}_{0.005}\right)_{2} \mathrm{O}_{3.98}: \mathrm{Zn}-\mathrm{d}$ & \multirow{3}{*}{ Cr-s- $\mathrm{O}_{2}$} & Cr-d-Air & \multirow{3}{*}{ Cr-s-N $N_{2}$} \\
\hline & $\mathrm{Zn}_{1.00}\left(\mathrm{Ga}_{0.995} \mathrm{Cr}_{0.005}\right)_{2} \mathrm{O}_{4.00}: \mathrm{Zn}-\mathrm{s}$ & & Cr-s-Air & \\
\hline & $\mathrm{Zn}_{1.02}\left(\mathrm{Ga}_{0.995} \mathrm{Cr}_{0.005}\right)_{2} \mathrm{O}_{4.02}: \mathrm{Zn}$-e & & Cr-e-Air & \\
\hline
\end{tabular}

\subsection{Optical Measurements}

Diffuse reflectance spectra of the samples were measured by using a scanning-type spectrophotometer (Shimadzu, UV3600) with a $\mathrm{BaSO}_{4}$-based integrating sphere. The scanning wavelength region was from 850 to $200 \mathrm{~nm}$. Photoluminescence (PL), photoluminescence excitation (PLE), and persistent luminescence excitation (PersLE) spectra were measured in a fluorescence spectrophotometer (Shimadzu, RF5000). Persistent luminescence excitation spectra were obtained by plotting $\mathrm{Cr}^{3+}$ persistent luminescence intensity in $60 \mathrm{~s}$ after excitation for $60 \mathrm{~s}$ at each excitation wavelength. Excitation wavelength was changed from 500 to $200 \mathrm{~nm}$ with a step of $-5 \mathrm{~nm}$. Before moving to the next excitation wavelength, a waiting time of $10 \mathrm{~min}$ was set to reduce the effect of the last excitation. Thermoluminescence (TL) glow curves of $\mathrm{Cr}^{3+}$ emission (around $695 \mathrm{~nm}$ ) were recorded using a silicon photodiode (Electro-Optical System Inc., S-025-H). A bandpass filter (350-750 nm) and a long-pass filter (> $580 \mathrm{~nm}$ ) were fixed before the silicon photodiode to cut off the noise. The samples were first cooled to $100 \mathrm{~K}\left(-173{ }^{\circ} \mathrm{C}\right)$ and exposed to a $300 \mathrm{~W}$ xenon lamp (Asahi Spectra, MAX 302) in an ultra-violet (UV) mirror module (250 to $380 \mathrm{~nm}$ ) for $5 \mathrm{~min}$. After another 5 min of waiting time, the samples were heated to $600 \mathrm{~K}\left(327^{\circ} \mathrm{C}\right)$ in a heating rate of $10 \mathrm{~K} /{ }^{\circ} \mathrm{C}$. The persistent luminescence decay curves at room temperature ( $\mathrm{RT}, 20^{\circ} \mathrm{C}$ ) were recorded by using the same silicon photodiode after the samples were excited by the same xenon lamp in the UV module for $5 \mathrm{~min}$. Then, the afterglow intensity was converted to an absolute intensity (radiance, in unit of $\mathrm{mW} \cdot \mathrm{sr}^{-1} \cdot \mathrm{m}^{-2}$ ) by using a CCD spectrometer (B\&W Tek, Glacier X) calibrated by Konica-Minolta company. 


\section{Results and Discussion}

\subsection{Band-gap absorption and self-activated emission in non- doped $\mathrm{Zn}_{\mathrm{x}} \mathrm{Ga}_{2} \mathrm{O}_{3+\mathrm{x}}$}

In order to evaluate the optical band-gap, the diffuse reflectance $\left(R_{\infty}\right)$ of the non-doped $\mathrm{Zn}_{\mathrm{x}} \mathrm{Ga}_{2} \mathrm{O}_{3+\mathrm{x}}$ pellets were converted to a Kubelka-Munk function $F\left(R_{\infty}\right)$ according to: ${ }^{38}$

$$
\boldsymbol{F}\left(\boldsymbol{R}_{\infty}\right)=\boldsymbol{S} \times\left(\mathbf{1}-\boldsymbol{R}_{\infty}\right)^{2} /\left(2 \times \boldsymbol{R}_{\infty}\right) .
$$

As an approximation, the diffusion coefficient $S$ was treated independent on wavelength. Then a $\left(\mathrm{h} v^{*} F\left(R_{\infty}\right)\right)^{2}$-hv plot was made according to an expression proposed by Tauc: ${ }^{39}$

$$
\left(\mathrm{h} v \times F\left(R_{\infty}\right)\right)^{2}=A \times\left(h v-E_{g}\right) .
$$

The values of the band-gap energy can be read from the intercepts of fitted straight lines.

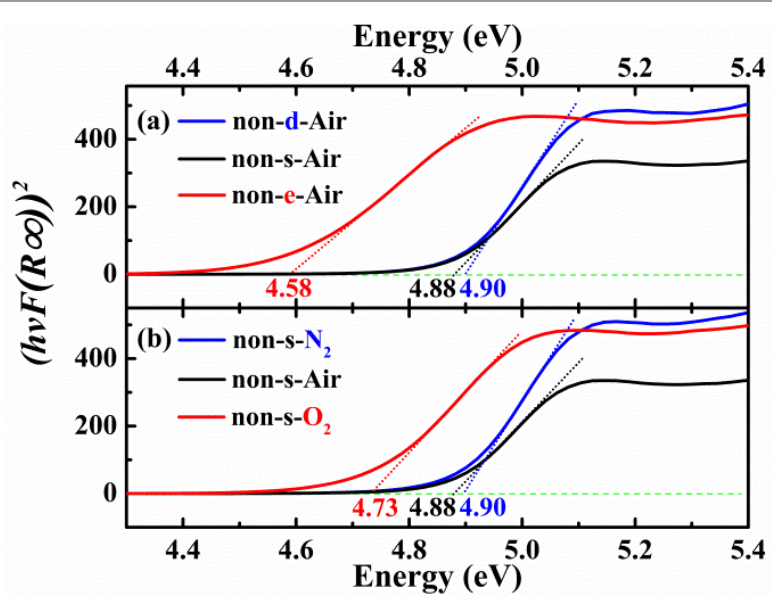

Fig. $2\left(\mathrm{~h} v^{*} F\left(R_{\infty}\right)\right)^{2}$-h $v$ plot of the non-doped $\mathrm{Zn}_{\mathrm{x}} \mathrm{Ga}_{2} \mathrm{O}_{3+\mathrm{x}}$ samples. Band-gap energy for each sample was estimated from the intercept of a fitted straight line. The optical band-gap energy decreased in the non-e-Air and non-s- $\mathrm{O}_{2}$ samples.

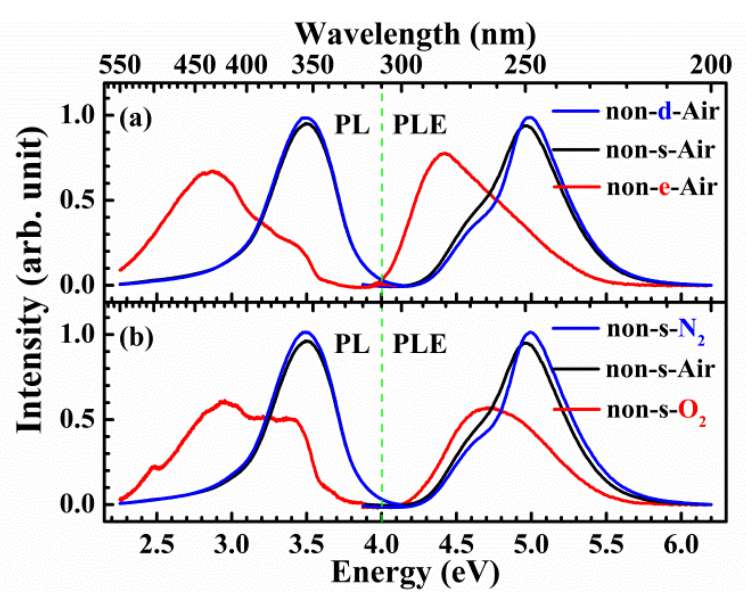

Fig. 3 PL and PLE spectra of the non-doped $\mathrm{Zn}_{\mathrm{x}} \mathrm{Ga}_{2} \mathrm{O}_{3+\mathrm{x}}$ samples. Top abscissa and bottom abscissa in each figure are scaled in wavelength $(\mathrm{nm})$ and energy $(\mathrm{eV})$ respectively. Excitation wavelength for the PL spectra (left part) was $250 \mathrm{~nm}$; monitoring wavelength for the PLE spectra (right part) was $360 \mathrm{~nm}$.
The fitting results of the three samples with different compositions (molar ratio of $\mathrm{Zn}$ to $\mathrm{Ga}$ ) are given in Fig. 2(a). The sample with Zn deficiency (blue) showed a band-gap of $4.90 \mathrm{eV}$. The band-gap energy decreased to 4.88 and $4.58 \mathrm{eV}$ when the molar ratio of $\mathrm{Zn}$ to Ga was varied to stoichiometric (black) and $\mathrm{Zn}$ excess (red), respectively. The effect of atmosphere $\left(\mathrm{P}_{\mathrm{O} 2}\right)$ on the band-gap energy is shown in Fig. 2(b). The band-gap decreased from $4.90,4.88$ to $4.74 \mathrm{eV}$ when the applied atmosphere for the solid state reaction was varied from $\mathrm{N}_{2}$ (blue), Air (black), to $\mathrm{O}_{2}$ (red).

In Fig. 3(a) and (b), the PL and PLE spectra of the nondoped $\mathrm{Zn}_{\mathrm{x}} \mathrm{Ga}_{2} \mathrm{O}_{3+\mathrm{x}}$ are given. The PLE spectra in the non-d-Air (right and top, blue) and non-s- $\mathrm{N}_{2}$ samples (right and bottom, blue) showed excitation bands maximizing at approximately $5.00 \mathrm{eV}$ (248 nm) due to optical band-gap transitions. The excitation bands red-shifted to $4.96 \mathrm{eV}(250 \mathrm{~nm})$ in the non-sAir sample (right, black), and further moved to $4.43 \mathrm{eV}$ $(280 \mathrm{~nm})$ in the non-e-Air sample (right and top, red) and 4.59 $\mathrm{eV}(270 \mathrm{~nm})$ in the non-s- $\mathrm{O}_{2}$ sample (bottom and right, red). The variation of PLE bands is consistent with the results in the absorption spectra (Fig. 2). The PL spectra (left part of Fig. 3) of the non-doped $\mathrm{Zn}_{\mathrm{x}} \mathrm{Ga}_{2} \mathrm{O}_{3+\mathrm{x}}$ samples showed self-activated emissions in the UV and visible regions. The emission bands shifted towards lower energy in the sample with Zn excess (left and top, red) or in the one prepared in $\mathrm{O}_{2}$ atmosphere (left and bottom, red) compared with other samples.

Schematic energy level diagrams of the non-doped $\mathrm{Zn}_{\mathrm{x}} \mathrm{Ga}_{2} \mathrm{O}_{3{ }^{+} \mathrm{x}}$ samples are depicted in Fig. 4. The HRBE concept was used where the top of the VB was defined as zero of energy. According to the results of absorption, PLE and PL spectra, the energies of band-gap absorption and self-activated emission in the non-d-Air and non-s- $\mathrm{N}_{2}$ samples were approximately 4.9 and $3.5 \mathrm{eV}$, respectively; the energies decreased and covered broader regions in 4.4 4.9 eV for bandgap absorption and 3.0 3.5 eV for self-activated emission. The decrease was attributed to lowering of the lowest component (bottom) of CB as shown in Fig. 4.
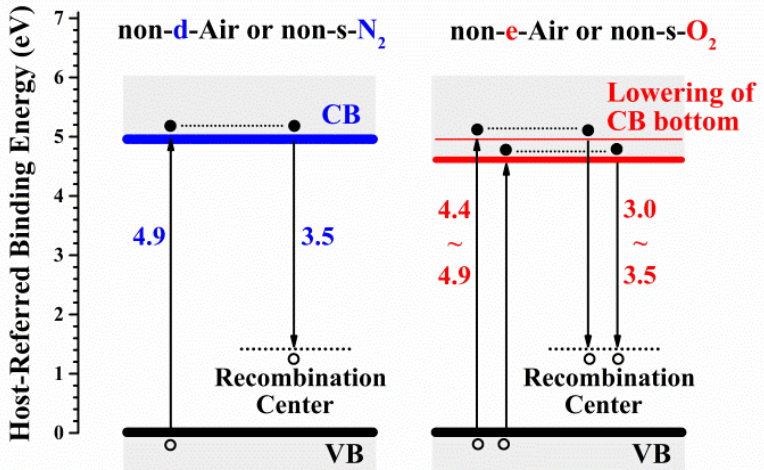

Fig. 4 Energy level diagram of the non-doped $\mathrm{Zn}_{\mathrm{x}} \mathrm{Ga}_{2} \mathrm{O}_{3+\mathrm{x}}$ crystals based on absorption, PL and PLE spectra. The VB top was defined as zero of energy. Redshift of band-gap absorption and self-activated emission was attributed to lowering of the CB bottom. 
It is known that the $\mathrm{ZnGa}_{2} \mathrm{O}_{4}$ crystalizes in an ideal normal spinel under ambient pressure, i.e. $\mathrm{Zn}$ and Ga ions occupy tetrahedral and octahedral sites, respectively. ${ }^{40-44}$ However, real $\mathrm{ZnGa}_{2} \mathrm{O}_{4}$ crystals (by high-temperature sintering) should contain some degree of anti-site coordination, i.e., $\mathrm{Zn}^{2+}$ in octahedral sites $\left(\mathrm{Zn}_{\mathrm{Ga}}{ }\right)$ and $\mathrm{Ga}^{3+}$ in tetrahedral site $\left(\mathrm{Ga}_{\mathrm{Zn}}{ }\right){ }^{45-47}$ These defects, as compared to other defects, require much lower formation energy $(0.9 \mathrm{eV})$ according to Pandey et al.: ${ }^{48}$

$$
\mathrm{Zn}_{\mathrm{Zn}}^{\mathrm{x}}+\mathbf{G a}_{\mathrm{Ga}}^{\mathrm{x}} \stackrel{\text { high temperature }}{\longrightarrow} \mathbf{Z n}_{\mathbf{G a}}^{\prime}+\mathbf{G a}_{\mathrm{Zn}}^{\cdot}
$$

The concentration of the two anti-site defects also should be affected by compositional deviation from stoichiometry, or by different applied atmosphere. In a $\mathrm{Zn}_{\mathrm{x}} \mathrm{Ga}_{2} \mathrm{O}_{3+\mathrm{x}}$ spinel crystal with $\mathrm{Zn}$ excess or in higher oxygen partial pressure (e.g. $\mathrm{O}_{2}$ ), a defect reaction in Eq. (5) can be promoted, where the defect species of $\mathrm{Zn}_{\mathrm{Ga}}^{\prime}$ is populated. On the other hand, in $\mathrm{Zn}_{\mathrm{x}} \mathrm{Ga}_{2} \mathrm{O}_{3+\mathrm{x}}$ crystals with composition of $\mathrm{Zn}$ deficiency or in lower oxygen partial pressure (e.g. $\mathrm{N}_{2}$ ), a defect reaction in Eq. (6) is promoted and the number of defect species of $\mathrm{Ga}_{\mathrm{Zn}}$ is increased.

$$
\begin{gathered}
3 \mathrm{ZnO}+\frac{1}{2} \mathrm{O}_{2} \stackrel{\mathrm{ZnGa}_{2} \mathrm{O}_{4}}{\longrightarrow} 2 \mathrm{Zn}_{\mathrm{Ga}}^{\prime}+\mathrm{Zn}_{\mathrm{Zn}}^{\mathrm{x}}+40_{0}^{\mathrm{x}}+2 \mathrm{~h}^{\bullet} \\
3 \mathrm{Ga}_{2} \mathrm{O}_{3} \stackrel{\mathrm{ZnGa}_{2} \mathrm{O}_{4}}{\longrightarrow} 2 \mathrm{Ga}_{\mathrm{Zn}}^{\cdot}+4 \mathrm{Ga}_{\mathrm{Ga}}^{\mathrm{x}}+80_{0}^{\mathrm{x}}+\frac{1}{2} \mathrm{O}_{2} \uparrow+2 \mathrm{e}^{\prime}
\end{gathered}
$$

We notice that the decrease of the band-gap was observed in both of the non-e-Air and non-s- $\mathrm{O}_{2}$ samples. Therefore, we consider that the formation of $\mathrm{Zn}_{\mathrm{Ga}}^{\prime}$ may be the reason of the CB lowering. Indeed, we cannot totally exclude the possibility of other defect species (e.g. $\mathrm{Zn}^{{ }_{\mathrm{i}}}$ or $\mathrm{V}^{{ }_{\mathrm{O}}}$ ), although the connections between the observed properties and these defects have not been found.

\subsection{Redox effects of $\mathrm{Cr}$ ions induced by compositional deviation from stoichiometry}

The Cr-doped $\mathrm{Zn}_{\mathrm{x}} \mathrm{Ga}_{2} \mathrm{O}_{3+\mathrm{x}}$ crystals show broad absorption bands peaked at around 560, 420, and $280 \mathrm{~nm}$ due to ${ }^{4} \mathrm{~A}_{2} \rightarrow{ }^{4} \mathrm{~T}_{2}$, ${ }^{4} \mathrm{~A}_{2} \rightarrow{ }^{4} \mathrm{~T}_{1}$, and ${ }^{4} \mathrm{~A}_{2} \rightarrow{ }^{4} \mathrm{~T}_{1}\left({ }^{4} \mathrm{P}\right)$ electronic transitions of $\mathrm{Cr}^{3+}$ ions. The Kubelka-Munk function, which is proportional to the absorption coefficient, can be used to quantify the concentration of $\mathrm{Cr}^{3+}$ ions. As shown in Fig. 5 (a), when the composition is varied from $\mathrm{Zn}$ excess to $\mathrm{Zn}$ deficiency, the absorption coefficient of $\mathrm{Cr}^{3+}$ decreases, indicating a reduction of $\mathrm{Cr}^{3+}$ concentrations in the sample with $\mathrm{Zn}$ deficiency. In Fig. 5(b), the absorption coefficient of $\mathrm{Cr}^{3+}$ also decreases from the sample prepared in $\mathrm{O}_{2}\left(\mathrm{Cr}-\mathrm{s}-\mathrm{O}_{2}\right)$ to that prepared in $\mathrm{N}_{2}$ (Cr-s$\mathrm{N}_{2}$ ).

Cr ions are expected to dominate in the $\mathrm{Cr}^{3+}$ valence state in the $\mathrm{ZnGa}_{2} \mathrm{O}_{4}$ spinel crystals as luminescent centers. However, abnormal state can be formed, as Peng's model suggests, in a case when there is a driving force for the stabilization of the abnormal state and the total free energy is reduced. ${ }^{49}$ As discussed in Sec. 4.1, in the sample with composition of $\mathrm{Zn}$ deficiency or in the one prepared in $\mathrm{N}_{2}$, the defect reaction of Eq. (6) is promoted. Notice that additional negative electrons $\left(\mathrm{e}^{\prime}\right)$ are created in this reaction. These electrons can combine with $\mathrm{Cr}^{3+}$ ions incorporated in $\mathrm{Ga}^{3+}$ sites $\left(\mathrm{Cr}_{\mathrm{Ga}}^{\mathrm{x}}\right)$ and reduce them into $\mathrm{Cr}^{2+}\left(\mathrm{Cr}_{\mathrm{Ga}}{ }^{2}\right)$, as shown in Eq. (7). The decrease of the $\mathrm{Cr}^{3+}$ absorption coefficient in the Cr-d-Air sample may be due to such "self-reduction effect" in the sample with $\mathrm{Zn}$ deficiency. For the sample with $\mathrm{Zn}$ excess or the one prepared in $\mathrm{O}_{2}$, the defect reaction of Eq. (5) is promoted. Because of the resultant positive holes $\left(\mathrm{h}^{\circ}\right)$, an oxidizing reaction in Eq. (8) can keep more $\mathrm{Cr}$ ions in the $\mathrm{Cr}^{3+}$ state.

$$
\begin{aligned}
\mathrm{Cr}_{\mathrm{Ga}}^{\mathrm{x}}+\mathbf{e}^{\prime} \rightarrow \mathrm{Cr}_{\mathrm{Ga}}^{\prime} \\
\mathrm{Cr}_{\mathrm{Ga}}^{\prime}+\mathbf{h}^{\bullet} \rightarrow \mathrm{Cr}_{\mathrm{Ga}}^{\mathrm{x}}
\end{aligned}
$$

In order to support the argument of the self-redox effect, electron spin resonance (ESR) measurements were performed in the Cr-doped $\mathrm{Zn}_{\mathrm{x}} \mathrm{Ga}_{2} \mathrm{O}_{3+\mathrm{x}}$ samples. The ESR spectra at $\mathrm{X}$ band frequency $(9.10 \mathrm{GHz})$ showed a resonance absorption at approximate $0.32 \mathrm{mT}$ at room temperature. This absorption was attributed to nearest-neighbour $\mathrm{Cr}^{3+}$ pairs in the spinel $\mathrm{Zn}_{\mathrm{x}} \mathrm{Ga}_{2} \mathrm{O}_{3+\mathrm{x}}$ crystals. ${ }^{50-52}$ The ESR spectra in the Cr-e-Air and $\mathrm{Cr}-\mathrm{s}-\mathrm{O}_{2}$ samples showed larger intensity of the resonance absorption, which confirmed higher concentration of $\mathrm{Cr}^{3+}$ ions in these two samples. It is note that the $\mathrm{Cr}^{2+}$ concentration should increase in the $\mathrm{Cr}-\mathrm{d}$-Air and Cr-s- $\mathrm{N}_{2}$ samples when the $\mathrm{Cr}^{3+}$ concentration decreases due to the reduction effect. Unfortunately, quantitative evaluation of $\mathrm{Cr}^{2+}$ concentration in the $\mathrm{Cr}$-doped $\mathrm{Zn}_{\mathrm{x}} \mathrm{Ga}_{2} \mathrm{O}_{3+\mathrm{x}}$ samples was unavailable in the absorption, PL, PL spectra and ESR measurements.

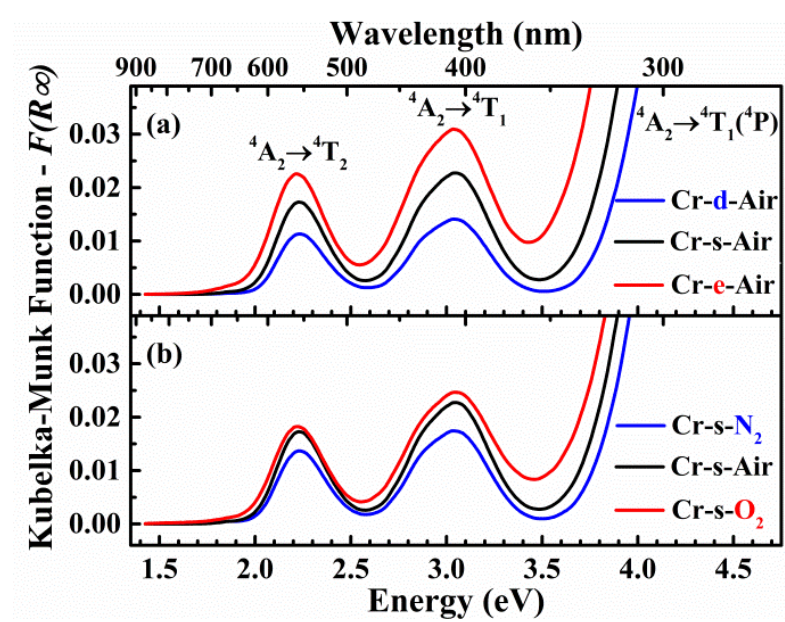

Fig. 5 Kubelka-Munk plot of the Cr-doped $\mathrm{Zn}_{\mathrm{x}} \mathrm{Ga}_{2} \mathrm{O}_{3+\mathrm{x}}$ crystals. Electronic transitions from ground state $\left({ }^{4} \mathrm{~A}_{2}\right)$ to various excited states $\left({ }^{4} \mathrm{~T}_{2},{ }^{4} \mathrm{~T}_{1}\right.$, and $\left.{ }^{4} \mathrm{~T}_{1}\left({ }^{4} \mathrm{P}\right)\right)$ of $\mathrm{Cr}^{3+}$ ion are notated. 


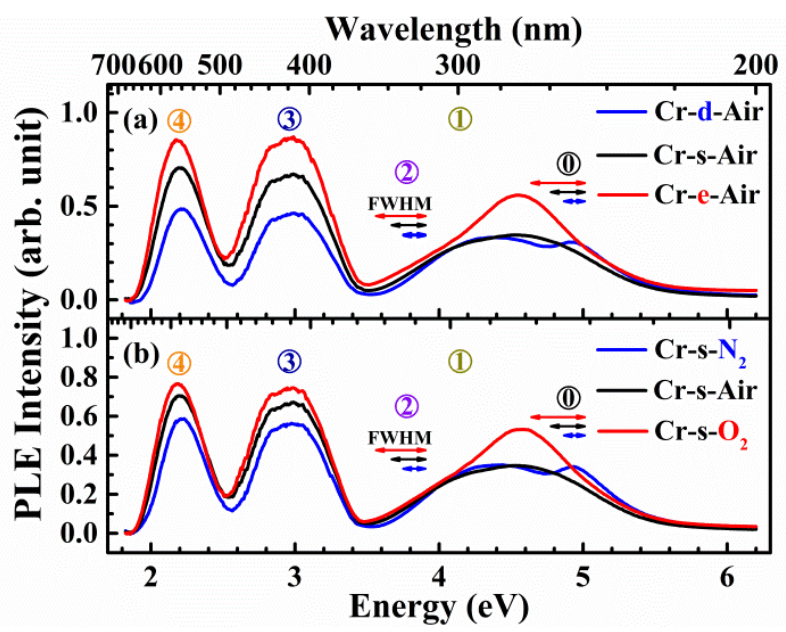

Fig. 6 PLE spectra of the $\mathrm{Cr}$-doped $\mathrm{Zn}_{\mathrm{x}} \mathrm{Ga}_{2} \mathrm{O}_{3+\mathrm{x}}$ samples. Monitoring wavelength was $695 \mathrm{~nm}(1.78 \mathrm{eV})$.

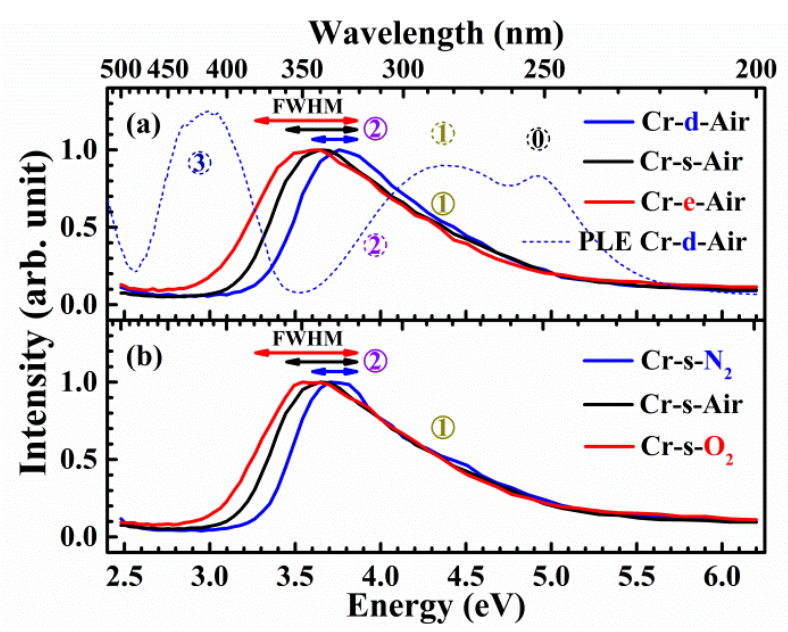

Fig. 7 Persistent luminescence excitation spectra (solid curves) of Cr-doped samples at $20^{\circ} \mathrm{C}$. The persistent luminescence intensity in $60 \mathrm{~s}$ after excitation as a function of excitation wavelength was plotted. A PLE spectrum of the Cr-d-Air sample (dash curve) was added in (a) to compare the relative intensity of different transitions.

\subsection{Variation of PL and persistent luminescence in the Cr-doped} $\mathrm{Zn}_{\mathrm{x}} \mathrm{Ga}_{2} \mathrm{O}_{3+\mathrm{x}}$ crystals

Under excitation by UV or visible light, the Cr-doped $\mathrm{Zn}_{\mathrm{x}} \mathrm{Ga}_{2} \mathrm{O}_{3+\mathrm{x}}$ samples showed several emission peaks at around $700 \mathrm{~nm}$ due to ${ }^{2} \mathrm{E} \rightarrow{ }^{4} \mathrm{~A}_{2}$ transitions of $\mathrm{Cr}^{3+}$. One single peak at $695 \mathrm{~nm}\left(\mathrm{~N}_{2}\right.$ line) was attributed to $\mathrm{Cr}^{3+}$ in distorted octahedral sites; other peaks at 688 ( $\mathrm{R}$ line), 679, $708 \mathrm{~nm}$ etc. (phonon side bands, PSB) were originated from $\mathrm{Cr}^{3+}$ in ideal octahedral sites. $^{53-55}$

The PLE spectra of the $\mathrm{Cr}$-doped $\mathrm{Zn}_{\mathrm{x}} \mathrm{Ga}_{2} \mathrm{O}_{3+\mathrm{x}}$ samples are shown in Fig. 6. The bands at short wavelength (designated as band 0) were attributed to the band-gap absorption. This band shifts from $250 \mathrm{~nm}(4.96 \mathrm{eV})$ in the Cr-d-Air and Cr-s- $\mathrm{N}_{2}$ samples to $280 \mathrm{~nm}(4.42 \mathrm{eV})$ in the Cr-e-Air and $\mathrm{Cr}-\mathrm{s}-\mathrm{O}_{2}$ samples, which is consistent with those in the non-doped $\mathrm{Zn}_{\mathrm{x}} \mathrm{Ga}_{2} \mathrm{O}_{3+\mathrm{x}}$ crystals (Fig. 3). Another band at around $340 \mathrm{~nm}$ (3.6 eV) (band 2) was attributed to an electronic transition from
GS of $\mathrm{Cr}^{3+}$, i.e. ${ }^{4} \mathrm{~A}_{2}$ level to $\mathrm{CB}$ of the host. This band shifts to lower energy in the Cr-e-Air and Cr-s- $\mathrm{O}_{2}$. Other bands at around $280 \mathrm{~nm}$ (4.43 eV) (band 1), $420 \mathrm{~nm}$ (2.95eV) (band 3), and $560 \mathrm{~nm}(2.11 \mathrm{eV}$ ) (band 4) due to 3d-3d transitions from ${ }^{4} \mathrm{~A}_{2}$ to ${ }^{4} \mathrm{~T}_{1}\left({ }^{4} \mathrm{P}\right),{ }^{4} \mathrm{~T}_{1}$, and ${ }^{4} \mathrm{~T}_{2}$ of $\mathrm{Cr}^{3+}$ were also detected in the PLE spectra. The energy of these 3d-3d transitions showing very weak dependence on the preparing condition (composition or atmosphere), are ignorable compared with the variation in ${ }^{4} \mathrm{~A}_{2} \rightarrow \mathrm{CB}$ and $\mathrm{VB} \rightarrow \mathrm{CB}$ transition energies (band 0 and band 2).

The PersLE spectra of the Cr-doped $\mathrm{Zn}_{\mathrm{x}} \mathrm{Ga}_{2} \mathrm{O}_{3+\mathrm{x}}$ samples in Fig. 7 showed broad bands from $400 \mathrm{~nm}(3.05 \mathrm{eV})$ to $270 \mathrm{~nm}$ (4.59 eV). These bands have two components: ${ }^{4} \mathrm{~A}_{2} \rightarrow \mathrm{CB}$ (band 2) and ${ }^{4} \mathrm{~A}_{2} \rightarrow{ }^{4} \mathrm{~T}_{1}\left({ }^{4} \mathrm{P}\right)$ transition (band 1). Different from the PLE spectra, the ${ }^{4} \mathrm{~A}_{2} \rightarrow \mathrm{CB}$ transition (band 2) in PersLE spectra shows much higher intensity than the other bands. Also, a redshift of the ${ }^{4} \mathrm{~A}_{2} \rightarrow \mathrm{CB}$ transitions (band 2) in the Cr-e-Air and $\mathrm{Cr}-\mathrm{s}-\mathrm{O}_{2}$ samples was observed as compared with the same transitions in the Cr-d-Air and Cr-s- $\mathrm{N}_{2}$ samples. The bands 0,3 , and 4 present in the PLE spectra could be hardly detected in Fig. 7.

Based on the obtained results, the energy level diagram in Fig. 8 including $\mathrm{CB}, \mathrm{VB}$, and various energy levels of $\mathrm{Cr}^{3+}$ is constructed. The ${ }^{4} \mathrm{~A}_{2} \rightarrow \mathrm{CB}$ transition (band 2) provides the energy location of the ${ }^{4} \mathrm{~A}_{2}$ level (GS of $\mathrm{Cr}^{3+}$ ) below the bottom of the CB. The ES of $\mathrm{Cr}^{3+}$ can then be located using the PLE spectra. For example, in the Cr-d-Air or Cr-s- $\mathrm{N}_{2}$ samples (Fig. 8 , left part), the energy difference between ${ }^{4} \mathrm{~A}_{2}$ and the $\mathrm{CB}$ bottom is approximately $3.7 \mathrm{eV}$. The ${ }^{4} \mathrm{~T}_{1}\left({ }^{4} \mathrm{P}\right)$ level is $4.4 \mathrm{eV}$ above the ${ }^{4} \mathrm{~A}_{2}$ level and located inside the $\mathrm{CB}$. On the other hand, the ${ }^{4} \mathrm{~T}_{1}$ and ${ }^{4} \mathrm{~T}_{2}$ levels are lower than CB. Consequently, electron transfer through the $\mathrm{CB}$ to the traps can be realized by excitation of ${ }^{4} \mathrm{~A}_{2} \rightarrow{ }^{4} \mathrm{~T}_{1}\left({ }^{4} \mathrm{P}\right.$ ) (band 1 ) and ${ }^{4} \mathrm{~A}_{2} \rightarrow \mathrm{CB}$ transitions (band 2), but will fail by excitation of ${ }^{4} \mathrm{~A}_{2} \rightarrow{ }^{4} \mathrm{~T}_{1}$ (band 3 ) and ${ }^{4} \mathrm{~A}_{2} \rightarrow{ }^{4} \mathrm{~T}_{2}$ transitions (band 4 ). Also, direct excitation into $\mathrm{CB}$ $\left({ }^{4} \mathrm{~A}_{2} \rightarrow \mathrm{CB} \rightarrow\right.$ traps) was proved as a more effective route for electron trapping than ${ }^{4} \mathrm{~A}_{2} \rightarrow{ }^{4} \mathrm{~T}_{1}\left({ }^{4} \mathrm{P}\right) \rightarrow \mathrm{CB} \rightarrow$ traps. A fast relaxation of ${ }^{4} \mathrm{~T}_{1}\left({ }^{4} \mathrm{P}\right)$ to ${ }^{4} \mathrm{~T}_{1}$ may decrease the electron trapping efficiency in the latter case.
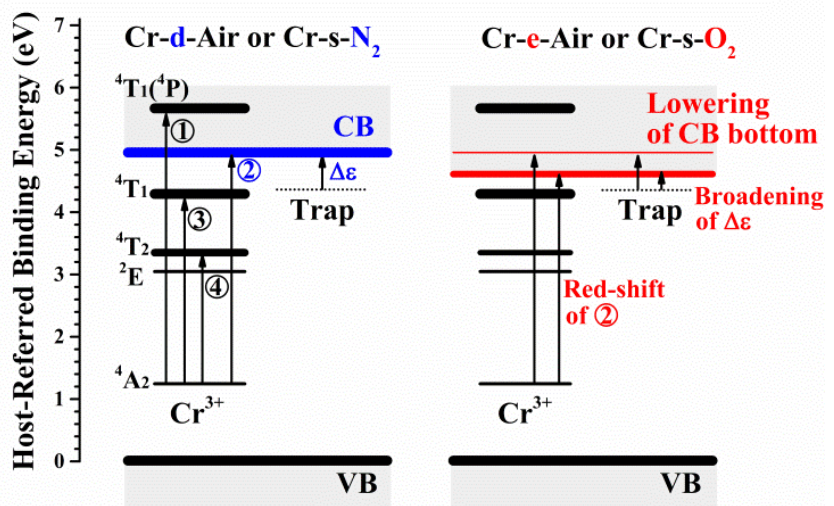

Fig. 8 Energy level diagrams of Cr-doped $\mathrm{Zn}_{\mathrm{x}} \mathrm{Ga}_{2} \mathrm{O}_{3+\mathrm{x}}$ crystals showing location of $\mathrm{Cr}^{3+}$ energy levels relative to $\mathrm{CB}$ and $\mathrm{VB}$ as well as the energy level of traps. 


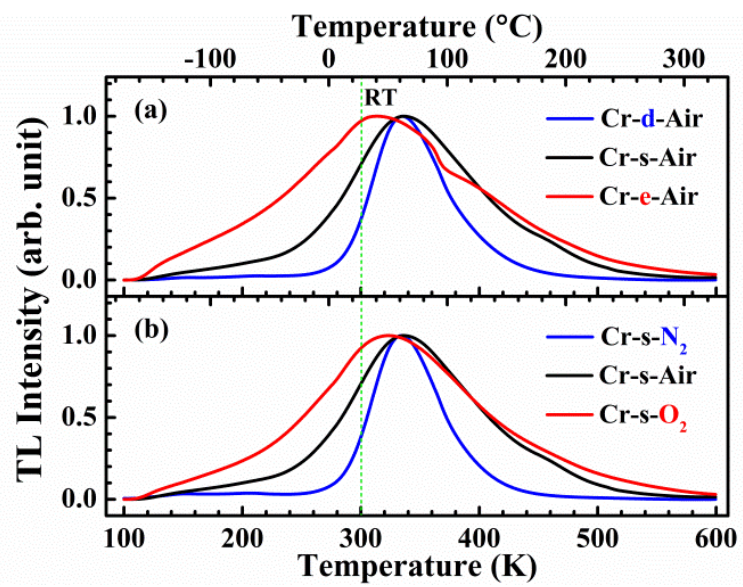

Fig. 9 TL glow curves of the Cr-doped $\mathrm{Zn}_{\mathrm{x}} \mathrm{Ga}_{2} \mathrm{O}_{3+\mathrm{x}}$ samples with heating rate of $10 \mathrm{~K} / \mathrm{min}$. Excitation source $(250-380 \mathrm{~nm})$ is from a $10 \mathrm{~W}$ xenon lamp. Detecting wavelengths are fixed in red region by using a $600-715 \mathrm{~nm}$ band-pass filter. TL intensity of each sample was normalized to 1 at peak temperature.

As shown in Fig. 4, when the molar ratio of $\mathrm{Zn}$ to Ga was varied from $\mathrm{Zn}$ deficiency to $\mathrm{Zn}$ excess or when the applied atmosphere was changed from $\mathrm{N}_{2}$ to $\mathrm{O}_{2}$, the CB bottom will be lowered by 0.3-0.4 eV. Based on the PersLE spectra the energy difference from ${ }^{4} \mathrm{~A}_{2}$ to the $\mathrm{CB}$ bottom decreases by approximately $0.3 \mathrm{eV}$ in the $\mathrm{Cr}$-e-Air or $\mathrm{Cr}$-s- $\mathrm{O}_{2}$ samples. The energy of the ${ }^{4} \mathrm{~A}_{2}$ level relative to $\mathrm{VB}$ top remains unchanged in different samples (Fig. 8).

TL glow curves of the Cr-doped $\mathrm{Zn}_{\mathrm{x}} \mathrm{Ga}_{2} \mathrm{O}_{3+\mathrm{x}}$ samples are shown in Fig. 9. Again, the glow curve in the $\mathrm{Cr}$-d-Air sample was similar to that in the Cr-s- $\mathrm{N}_{2}$ sample. The glow curves show a band peaked at approximately $340 \mathrm{~K}$ with narrow full width at half maximum (FWHM $=70 \mathrm{~K}$ ). The glow curves broaden in the Cr-e-Air and Cr-s- $\mathrm{O}_{2}$ samples $(\mathrm{FWHM}=180 \mathrm{~K})$ and slightly shifted to lower temperature.

The peak temperature and FWHM of the TL glow curves reflect trap depth (thermal activation energy, $\Delta \varepsilon$ ) and the trap depth distribution. As shown in Fig. 8, the change in $\Delta \varepsilon$ (decrease of the average value and broadening of the distribution) can be due to lowering of the CB bottom.

In Fig. 10, we compare the persistent luminescence decay curves of the $\mathrm{Cr}^{3+}$-doped $\mathrm{Zn}_{\mathrm{x}} \mathrm{Ga}_{2} \mathrm{O}_{3+\mathrm{x}}$ crystals after excitation by UV light (250-380 nm). The Cr-e-Air and Cr-s- $\mathrm{O}_{2}$ samples show higher intensity of persistent luminescence in the initial stage (the first $30 \mathrm{~s}$ ) and decay in a faster rate than the Cr-d-Air and $\mathrm{Cr}-\mathrm{s}-\mathrm{N}_{2}$ samples. The persistent luminescence (in radiance) of the Cr-d-Air and Cr-s- $\mathrm{N}_{2}$ samples $3600 \mathrm{~s}$ after removal of the UV light was several times higher than the Cr-e-Air and Cr-s$\mathrm{O}_{2}$ samples.

As discussed in Sec. 4.2, the composition and atmosphere showed a redox effect on the valence state of $\mathrm{Cr}$ ions. More $\mathrm{Cr}$ ions were stabilized in higher valence state, $\mathrm{Cr}^{3+}$ state in the Cre-Air and $\mathrm{Cr}-\mathrm{s}-\mathrm{O}_{2}$ samples. These two samples showed higher intensity of PL and persistent luminescence in the initial stage. However, the detrapping rate in the $\mathrm{Cr}$-e-Air and $\mathrm{Cr}-\mathrm{s}-\mathrm{O}_{2}$ is too fast, which may be due to lower and broad distribution of $\Delta \varepsilon$ as shown in Fig. 8.

From the viewpoint of persistent phosphors used at RT, a narrow distribution of $\Delta \varepsilon$ at approximately $0.6 \mathrm{eV}$ (corresponding narrow glow peaks centred at $300-350 \mathrm{~K}$ ) is expected. ${ }^{10}$ Slight Zn deficiency in the composition should be adopted to keep a narrow distribution of $\Delta \varepsilon$. However, we have to consider the self-reduction effect and decrease of $\mathrm{Cr}^{3+}$ concentration in the composition of Zn deficiency. In Ref. 19, it was shown that $\mathrm{Bi}_{2} \mathrm{O}_{3}$ is a good stabilizer for $\mathrm{Cr}^{3+}$ state in a CrBi-codoped $\mathrm{Zn}_{0.98} \mathrm{Ga}_{2} \mathrm{O}_{3.98}$ sample. The co-doped sample showed greatly enhanced persistent luminescence because of a narrow glow peak at $330 \mathrm{~K}$ as well as a much higher concentration of stabilized $\mathrm{Cr}^{3+}$ ions.

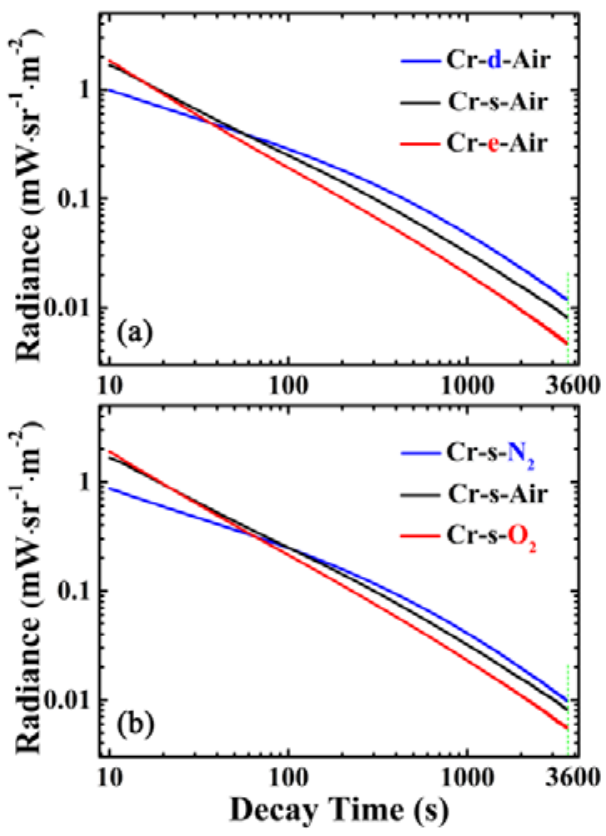

Fig. 10 Persistent luminescence decay curves of the $\mathrm{Cr}^{3+}$-doped $\mathrm{Zn}_{\mathrm{x}} \mathrm{Ga}_{2} \mathrm{O}_{3+\mathrm{x}}$ crystals after excitation of UV light $(250-380 \mathrm{~nm})$ for $5 \mathrm{~min}$. The intensity of persistent luminescence was converted to radiance (absolute value).

\section{Conclusion}

In the process of investigating optical properties in non-doped $\mathrm{Zn}_{\mathrm{x}} \mathrm{Ga}_{2} \mathrm{O}_{3+\mathrm{x}}(0.98 \leq \mathrm{x} \leq 1.02)$ crystals, decrease of band-gap energy due to lowering of $\mathrm{CB}$ bottom was observed in the sample with $2 \% \mathrm{Zn}$ excess in composition and in the sample prepared in $\mathrm{O}_{2}$ atmosphere. The similar lowering of CB bottom in these two samples may be due to significant formation of $\mathrm{Zn}_{\mathrm{Ga}}{ }_{\mathrm{Ga}}$ anti-sites considering the most probable defect chemical reactions in composition of $\mathrm{Zn}$ excess or high partial oxygen pressure. The lowering of CB bottom resulted in decrease and broader distribution of trap depth. Slight Zn deficiency in the composition should be adopted to keep narrow distribution and trap depth for longer persistent luminescence decay. However, the sample with composition of Zn deficiency showed a self- 
reduction effect on $\mathrm{Cr}$ ions into lower valence states. Effective measure should be taken to stabilize $\mathrm{Cr}$ ions in $\mathrm{Cr}^{3+}$ state.

\section{Acknowledgements}

This work was financially supported by a Grant-in-aid for Scientific Research for JSPS Fellows (No. 24-806).

\section{Notes and references}

${ }^{a}$ Graduate School of Human and Environmental Studies, Kyoto University, Kyoto, Japan. Fax: +81 75753 6694; Tel: +81 75753 6817; E-mail: zhuang.yixi.24c@st.kyoto-u.ac.jp

${ }^{b}$ Graduate School of Human and Environmental Studies, Kyoto University, Kyoto, Japan. Fax: +81 75753 6694; Tel: +81 75753 6817; E-mail: ueda.jumpei.5r@kyoto-u.ac.jp

${ }^{c}$ Graduate School of Human and Environmental Studies, Kyoto University, Kyoto, Japan. Fax: +81 75753 6694; Tel: +81 75753 6832; E-mail: tanabe.setsuhisa.4v@kyoto-u.ac.jp

${ }^{d}$ Delft University of Technology, Delft, The Netherlands. Fax: +31 15278

1336; Tel: +31 15278 1336; E-mail:p.dorenbos@tudelft.nl

1 S. Shionoya and W. M. Yen, Phosphor Handbook; CRC Press: Boca Raton, 1999.

2 S. Jutamulia, G. M. Storti, J. Lindmayer and W. Seiderman, Appl. Opt., 1990, 29, 4806.

3 R. Soref, Proc. IEEE, 1966, 54, 425.

4 H. Brito, J. Hölsä, T. Laamanen, M. Lastusaari, M. Malkamäki and L. Rodrigues, Opt. Mater. Express, 2012, 2, 371.

5 P. Smet, D. Poelman and M. Hehlen, Opt. Mater. Express, 2012, 2, 252.

6 Q. Chermont, C. Chanéac, J. Seguin, F. Pellé, S. Maîtrejean, J.-P. Jolivet, D. Gourier, M. Bessodes and D. Scherman, Proc. Natl. Acad. Sci. U.S.A., 2007, 104, 9266.

7 S. Hilderbrand and R. Weissleder, Curr. Opin. Chem. Biol., 2010, 14, 71.

8 R. Weissleder and V. Ntziachristos, Nat. Med., 2003, 9, 123.

9 K. Van den Eeckhout, P. Smet and D. Poelman, Materials, 2010, 3 , 2536.

10 T. Matsuzawa, Y. Aoki, N. Takeuchi and Y. Murayama, J. Electrochem. Soc., 1996, 143, 2670.

11 H. Takasaki, S. Tanabe and T. Hanada, J. Ceram. Soc. Jpn., 1996, 104, 322.

12 Y. Lin, Z. Tang, Z. Zhang and C. Nan, J. Eur. Ceram. Soc., 2003, 23, 175.

13 P. Dorenbos, Phys. Stat. Sol. (b), 2005, 242, R7.

4 D. Jia, W. Jia, D. Evans, W. Dennis, H. Liu, J. Zhu and W. Yen, J. Appl. Phys., 2000, 88, 3402.

5 P. Smet, N. Avci and D. Poelman, J. Electrochem. Soc., 2009, 156, H243.

6 A. Bessière, S. Jacquart, K. Priolkar, A. Lecointre, B. Viana and D. Gourier, Opt. Express, 2011, 19, 10131.

7 Z. Pan, Y. Lu and F. Liu, Nat. Mater., 2012, 11, 58.

8 M. Allix, S. Chenu, E. Véron, T. Poumeyrol, E. Kouadri-Boudjelthia, S. Alahraché, F. Porcher, D. Massiot and F. Fayon, Chem. Mater., 2013, 25, 1600.

19 Y. Zhuang, J. Ueda and S. Tanabe, Appl. Phys. Express, 2013, 6, 052602 .
20 A. Abdukayum, J. Chen, Q. Zhao and X. Yan, J. Am. Chem. Soc., 2013, 135, 14125

21 Y. Zhuang, J. Ueda and S. Tanabe, J. Mater. Chem. C, 2013, 1, 7849.

22 W. Yan, F. Liu, Y. Lu, X. Wang, M. Yin and Z. Pan, Opt. Express, 2010, 18, 20215

23 D. Jia, L. Lewis and X. Wang, Electrochem. Solid State Lett., 2010, 13, J32.

24 Y. Lu, F. Liu, Z. Gu and Z. Pan, J. Lumin., 2011, 131, 2784.

25 F. Liu, W. Yan, Y. Chuang, Z. Zhen, J. Xie and Z. Pan, Sci. Rep., 2013, 3, 1544.

26 N. Basavaraju, S. Sharma, A. Bessière, B. Viana, D. Gourier and K. Priolkar, J. Phys. D: Appl. Phys., 2013, 46, 375401.

27 K. Van den Eeckhout, D. Poelman and P. Smet, Materials, 2013, 6, 2789.

28 P. Dorenbos, Phys. Rev. B, 2012, 85, 165107.

29 F. You, A. Bos, Q. Shi, S. Huang and P. Dorenbos, Phys. Rev. B, 2012, 85, 115101.

30 P. Dorenbos, Phys. Rev. B, 2013, 87, 035118.

31 A. Bessière, R. A. Benhamou, G. Wallez, A. Leconintre and B. Viana, Acta Mater., 2012, 60, 6641.

32 S. Kaya, E. Karacaoglu and B. Karasu, Ceram. Int., 2012, 38, 3701.

33 E. Otal, A. Maegli, N. Vogel-Schäuble, B. Walfort, H. Hagemann, S. Yoon, A. Zeller and A. Weidenkaff, Opt. Mater. Express, 2012, 2, 405.

34 P. Smet, N. Avci, K. Van den Eeckhout and D. Poelman, Opt. Mater. Express, 2012, 2, 1306.

35 J. Ueda, K. Aishima, S. Nishiura and S. Tanabe, Appl. Phys. Express, 2011, 4, 042602.

36 Y. Chiang, D. Birnie and W. Kingery, Physical Ceramics; Wiley: Canada, 1997.

37 K. Korthout, K. Van den Eeckhout, J. Botterman, S. Nikitenko, D. Poelman and P. Smet, Phys. Rev. B, 2011, 84, 085140.

38 V. Dzimbeg-Malcic, Z. Barbaric-Mikocevic and K. Itric, Teh. Vjesn., 2011, 18, 117.

39 J. Tauc, Mater. Res. Bull., 1968, 3, 37.

40 S. Sampath and J. Cordaro, J. Am. Ceram. Soc., 1998, 81, 649.

41 H. Kawazoe and K. Ueda, J. Am. Ceram. Soc., 1999, 82, 3330.

42 S. Sampath, D. Kanhere and R. Pandey, J. Phys.: Condens. Matter, 1999, 11, 3635.

43 S. Karazhanov and P. Ravindran, J. Am. Ceram. Soc., 2010, 95, 3335.

44 F. Zerarga, A. Bouhemadou, R. Khenata and S. Bin-Omran, Soild State Sci., 2011, 13, 1638.

45 I. Jeong, H. Park and S. Mho, Solid State Commun., 1998, 105, 179.

46 J. Kim, H. Kang, W. Kim, J. Kim, J. Choi, H. Park, G. Kim, T. Kim, Y. Hwang, S. Mho, M. Jung and M. Han, Appl. Phys. Lett., 2003, 82, 2029.

47 J. Kim, H. Park, C. Chon, H. Moon and T. Kim, Solid State Commun., 2004, 129, 163.

48 R. Pandey, J. D. Gale, S. K. Sampath and J. M. Recio, J. Am. Ceram. Soc., 1999, 82, 3337.

49 M. Peng, J. Lei, L. Li, L. Wondraczek, Q. Zhang, J. Qiu, J. Mater. Chem. C, 2013, 1, 5303.

50 H. van den Boom, J. Henning and J. Damen, Solid State Commun., 1970, 8, 717.

51 J. Henning and J. Damen, Phys. Rev. B, 1971, 3, 3852. 
52 J. Henning, J. den Boef and G. van Gorkom, Phys. Rev. B, 1973, 7, 1825.

53 W. Mikenda and A. Preisinger, J. Lumin., 1981, 26, 53.

54 W. Mikenda and A. Preisinger, J. Lumin., 1981, 26, 67.

55 G. G. P. van Gorkom, J. C. M. Henning and R. P. van Stapele, Phys. Rev. B, 1973, 8, 955. 